\title{
PRECIPITATION AND SOFTENING BEHAVIOUR OF CAST, COLD ROLLED AND HOT ROLLING PRIOR TO COLD ROLLED AL-6MG ALLOY ANNEALED AT HIGH TEMPERATURE
}

\author{
M. S. Kaiser \\ Directorate of Advisory, Extension and Research Services \\ Bangladesh University of Engineering and Technology, Dhaka-1000, Bangladesh \\ Corresponding e-mail: mskaiser@iat.buet.ac.bd
}

\begin{abstract}
The effect of cast, cold rolling and hot rolling prior to cold rolling reduction on the hardness, electrical conductivity and grain size of annealed Al-6Mg alloys was studied. It was found that the hot rolling prior to cold rolling attend the higher strength due to precipitation of $\beta$-phase during hot rolling which hinder the dislocation movement. At higher temperature of annealing electrical resistivity decreses due to particle coarcening but in case of cast alloy it increases due to precipitation of $\beta$-phase. It is seen from the microstructure that the cold worked structures are comprised of elongated grains. It is also observed that the cold rolled alloy attained almost fully re-crystallized state after annealing at $400^{\circ} \mathrm{C}$ for 60 minutes.
\end{abstract}

Keywords: Al-Mg alloys, microstructure, hot rolling, cold rolling, annealing, hardness, electrical resistivity.

\section{INTRODUCTION}

Aluminum alloys with magnesium as the major alloying element constitute a group of non heat-treatable alloys with medium strength, high ductility, excellent corrosion resistance and weldability. Unfortunately, they belong to the group of non-heat treatable $\mathrm{Al}$ alloys which derive their strength mainly from solution strengthening and work hardening during deformation. Cold deformation is particularly effective in strengthening since restoration processes are thermally activated. Strength of Al-Mg alloys strongly increases with addition of $\mathrm{Mg}$. $\mathrm{Mg}$ has a high solubillity in solid solutions and therefore it provides the most effective enhancement of strength among all alloying additions in the aluminium solid solution $^{1-2}$. Recent technological advancement in aerospace, automotive, marine, construction and leisure industries has made the demand for materials having high strength to weight ratio, high specific modulus, good corrosion resistance and good thermal conductivity to be on the increase. The mechanical properties of this alloy are better when mechanically worked at temperatures below or above it recrystallization temperature. During cold working, dislocation motions within metal matrix are restricted resulting in strength increment as its shape is changed. Structural components made from such strengthened alloys are vital to the building, aerospace and transportation industries, as well as for the production of utensils for domestic use. Several studies have been carried out on wrought aluminum alloys to understand the effects of mechanical workings on its mechanical properties $^{3,4}$. The results show that both the hardness profile and bulk strength were enhanced with post rolling. In addition, the microstructural evolutions showed that post rolling not only reduces the grain size but also reduces the heterogeneity of microstructure across the longitudinal section. $\mathrm{Mg}$, like other solute elements, has a strong influence on recrystallization and grain growth. It also serves to reduce both the rate of growth and the final grain size ${ }^{5}$. Commercial $\mathrm{Al}-\mathrm{Mg}$ alloys also contain elements such as $\mathrm{Mn}, \mathrm{Fe}, \mathrm{Si}$ or $\mathrm{Cr}$ and Ti. These elements form the second phase particles due to a limited solubility in solid solutions. Although these elements have a minor influence on strength of Al alloys, they have a significant influence on annealing behaviour, i.e. they are an important parameter in the grain size control. Electrical conductivity is one of the most sensitive properties of $\mathrm{Al}$ alloys, being particularly responsive to changes in composition and temper. The electrical conductivity of these alloys is mainly dependent on the amount of magnesium dissolved and decreases almost linearly with concentration of $\mathrm{Mg}$ in a solution ${ }^{6}$.

The aim of this study was to determine the relation between the applied deformation and grain size of annealed $\mathrm{Al}-6 \mathrm{Mg}$ alloy as well as their precipitation behavior and electrical resistivity.

\section{EXPERIMENTAL}

The material used in the current study is a $\mathrm{Al}-\mathrm{Mg}$ alloys containing $6 \mathrm{wt} \% \mathrm{Mg}$ were prepared by Melting in a resistance heating pot furnace under the suitable flux cover (degasser, borax etc.). Commercially pure aluminium $(99.5 \%$ purity) was melted in a clay-graphite crucible. Magnesium ribbon $(99.7 \%$ purity) was then added into melt. The final temperature of the melt was maintained at $780 \pm 15^{\circ} \mathrm{C}$. Casting was done in $12.5 \mathrm{~mm} \times 50 \mathrm{~mm} \times 200 \mathrm{~mm}$ cast iron metal moulds preheated to $200^{\circ} \mathrm{C}$. The alloy was analysed by chemical and spectrochemical methods simul- 
taneously. The chemical compositions of the alloy are given in Table 1 . The cast samples were first ground properly to remove the oxide layer from the surface. Portions of alloy were kept in furnace at $350^{\circ} \mathrm{C}$ for 24 hours for homogenization of the alloy. Hot rolling by $50 \%$ of homogenized samples was carried out in a laboratory scale rolling mill. Rolling temperature was around $380^{\circ} \pm 5^{\circ} \mathrm{C}$. Cold rolling of the alloy, as cast and hot rolled were carried out with the above rolling mill at $75 \%$ reduction percentages. The samples in as cast, cold rolled and cold worked with prior hot working were annealing isothermally at various temperatures for different times ranging from 30 to 240 minutes. Vickers hardness of differently processed alloys was measured with a $5 \mathrm{~kg}$ load for assessing the softening effect of the alloy. An average of seven consistent readings was accepted as the representative hardness value of an alloy. Electrical conductivity of the cast alloy, cold worked and cold worked with prior hot working condition was measured. Surface finished samples of area $12 \mathrm{~mm} \times 12 \mathrm{~mm}$, were subjected to conductivity test using a Conductivity Meter, Type 979. Electric resistivity was then calculated from the measured values of conductivity. The alloys after different heat treatments are subjected to optical metallographic studies. The specimens were polished with alumina and etched with Keller's reagent and observed under a Versamet-II- Microscope. Scanning electron microscopy of the selected samples was carried out by a Jeol Scanning Electron Microscope, JSM-5200. Transmission Electron Microscopic studies of alloys in different conditions were carried out in Philips (CM12) Transmission Electron Microscope at an accelerating voltage $160 \mathrm{KV}$.

Table 1. Chemical composition of the experimental alloy ( $\mathrm{wt} \%$ )

\begin{tabular}{|c|c|c|c|c|c|c|}
\hline $\mathrm{Mg}$ & $\mathrm{Cu}$ & $\mathrm{Fe}$ & $\mathrm{Mn}$ & $\mathrm{Si}$ & $\mathrm{Zn}$ & $\mathrm{Al}$ \\
\hline 6.10 & 0.081 & 0.382 & 0.155 & 0.380 & 0.136 & $\mathrm{Bal}$ \\
\hline
\end{tabular}

\section{RESULTS AND DISCUSSION}

\section{Hardness}

Figures 1-3 show the isothermal annealing of the alloys at $200^{\circ} \mathrm{C}, 300^{\circ} \mathrm{C}$ and $400^{\circ} \mathrm{C}$ respectively. When the alloys are isothermally annealing at low temperature $200^{\circ} \mathrm{C}$ the hardness fall due to stress reliving of the alloys. Annealing at $300^{\circ} \mathrm{C}$, alloys show a very fast and steep decrease in hardness followed by a constant value due to recovery and recrystallisation. The rate and degree of initial softening is higher for cold rolling alloy. Annealing at higher temperature at $400^{\circ} \mathrm{C}$ shows the similar trend for all alloys. The initial softening shown in the isochronal annealing curve for the cast alloy is thought to be due to internal stress relieving of the rapidly solidified castings. In the cast condition the $\beta$-phase being already present in the

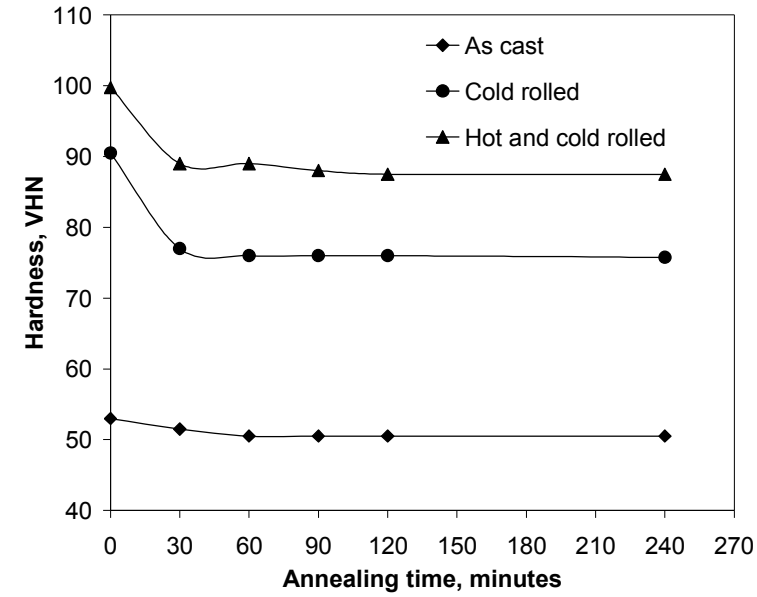

Figure 1. Variation of hardness of the alloys due to isothermally annealing at $200^{\circ} \mathrm{C}$.

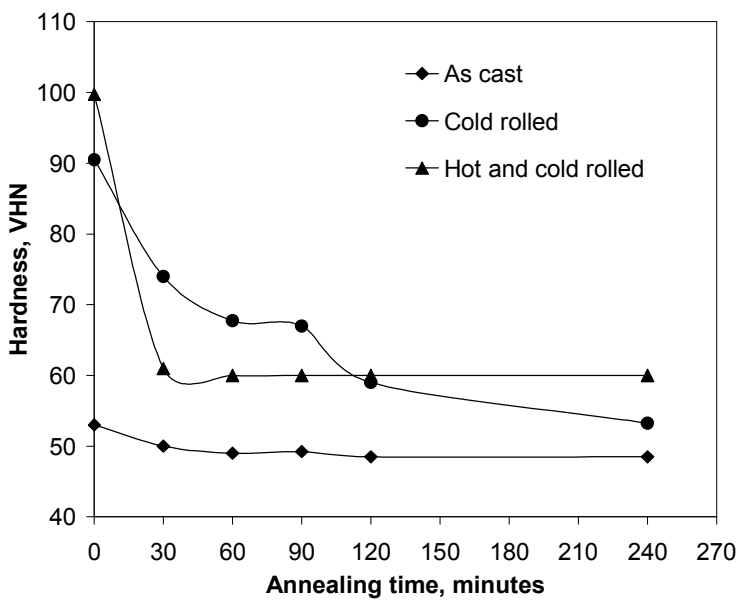

.Figure 2. Variation of hardness of the alloys due to isothermally annealing at $300^{\circ} \mathrm{C}$.

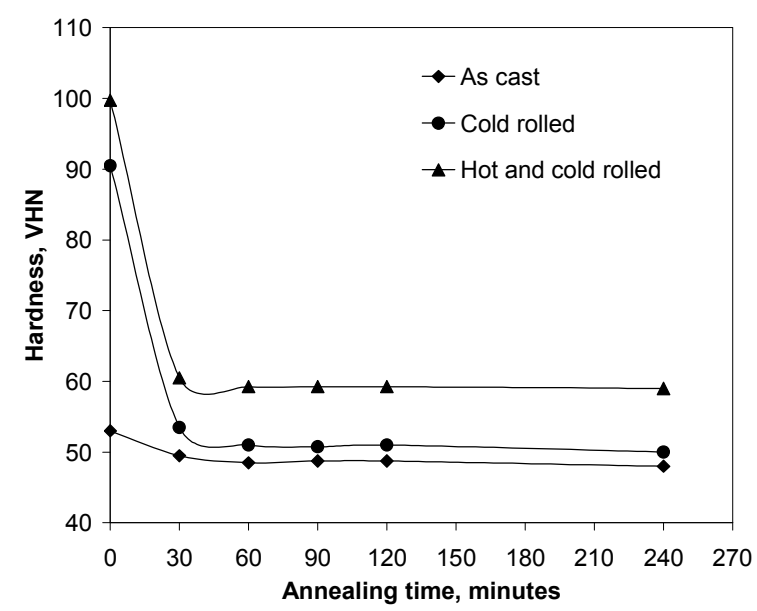

Figure 3. Variation of hardness of the alloys due to isothermally annealing at $400^{\circ} \mathrm{C}$.

microstructure of the matrix of the alloy, precipitation hardening due to the formation of aluminides of magnesium is not envisaged ${ }^{1}$. Annealing at $300^{\circ} \mathrm{C}$ the cold rolled alloy restricts to soffening due to fine precipitate of $\beta$-phase, beyond this softening occurses 
may be due to particle coarsening effect of the second phase. When the hot rolled alloy is cold rolled and then annealed, the alloy does not depict any ageing response. After the usual initial softening the hardness values remain more or less constant. The extent of initial softening is lower than that of the alloys cold rolled from as cast condition. The magnitude of initial hardness drop is a function of annealing temperature and is found to increase with increasing annealing temperature due to higher dislocation mobility. The hot rolling prior to cold rolling attends the higher strength due to precipitation of the $\beta^{\prime}$ and $\beta$ phase during hot rolling which hinder the dislocation movement.

\section{Electrical resistivity}

The variations of the resistivity values of the alloys at different annealing temperatures are shown Figs. 4 to 6 . At initial stage the hot rolling prior to cold rolling alloy shows the higher resistivity value. At $200^{\circ} \mathrm{C}$ the resistivity of the alloys drops initially and then holds a constant value for higher annealing time (Fig. 4). The rate of decreasing is higher for cold rolled alloys. Almost similar trend of variation in resistivity is found for annealing at $300^{\circ} \mathrm{C}$ (Fig. 5). The cold rolled alloy shows a double peak in resistivity. The resistivity curve for isothermal annealing at $400^{\circ} \mathrm{C}$ shows for the cast alloy, a steep increase in the initial period followed by a constant value. For the hot and cold rolled alloys shows the opposed nature of cast alloy that is a steep drop in the initial period followed by a constant value. On the contrary cold rolled alloy shows a two-stage increase in resistivity (Fig. 6). The initial drop in resistivity for the cast alloy is due to stress relieving in the alloys during annealing. The steep drop in resistivity of cold rolled alloys considered to be due to stress relieving and recovery of strain or dissolution of $\mathrm{Al}_{8} \mathrm{Mg}_{5}(\beta)$ phase already present in the matrix. At higher temperature the cast alloy shows the higher conductivity due to formation of the $\beta^{\prime}$ and $\beta$ phase. For the cold rolled alloy the increase of resistivity at the beginning of annealing is caused by the formation of GP zones (solute-cluster) and the second one for the metastable $\beta^{\prime}$ phase in Al-Mg alloy gives way to the formation of $\beta$-phase. Beyond this a lower electrical resistivity after annealing is a result of the combined effects of recovery and the dissolution of precipitate phases $^{6}$. A prior hot rolling does not show any dissolution peak for obvious reason of the existing precipitates getting dissolved during heating and soaking for hot working. The steady decrease in resistivity stems from particle coarsening, which reduces the number of scattering centers. Since precipitate coarsening is appreciable at high temperatures, the resistivity drop is also noticeable ${ }^{7}$.

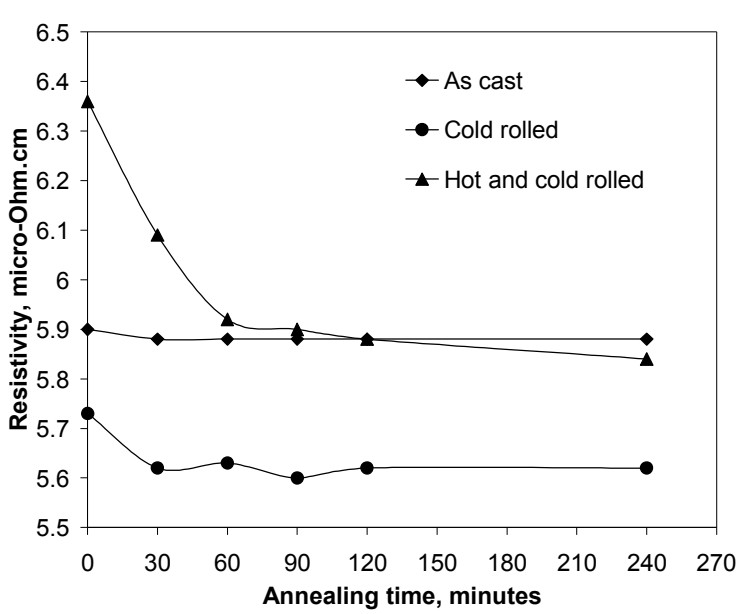

Figure 4. Variation of resistivity of the alloys due to isothermally annealing at $200^{\circ} \mathrm{C}$.

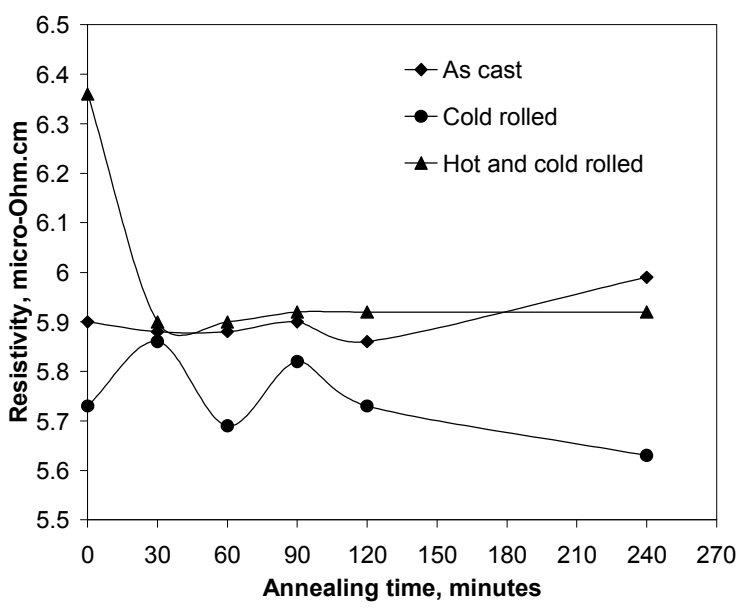

Figure 5. Variation of resistivity of the alloys due to isothermally annealing at $300^{\circ} \mathrm{C}$.

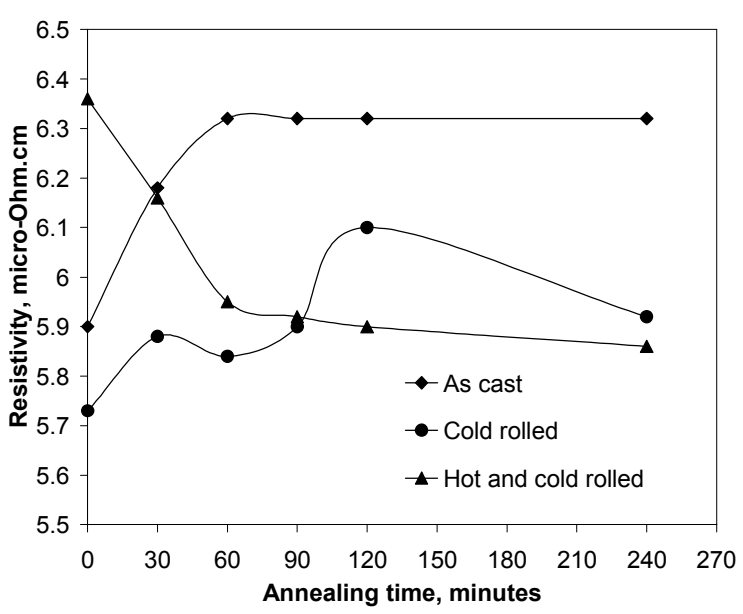

Figure 6. Variation of resistivity of the alloys due to isothermally annealing at $400^{\circ} \mathrm{C}$.

\section{Micrographs}

The cast microstructure reveals a typical equiaxed dendritic structure with some solute segregation and non-equilibrium solidification products at the inter-dendritic channel (Fig. 7a). The cold worked 

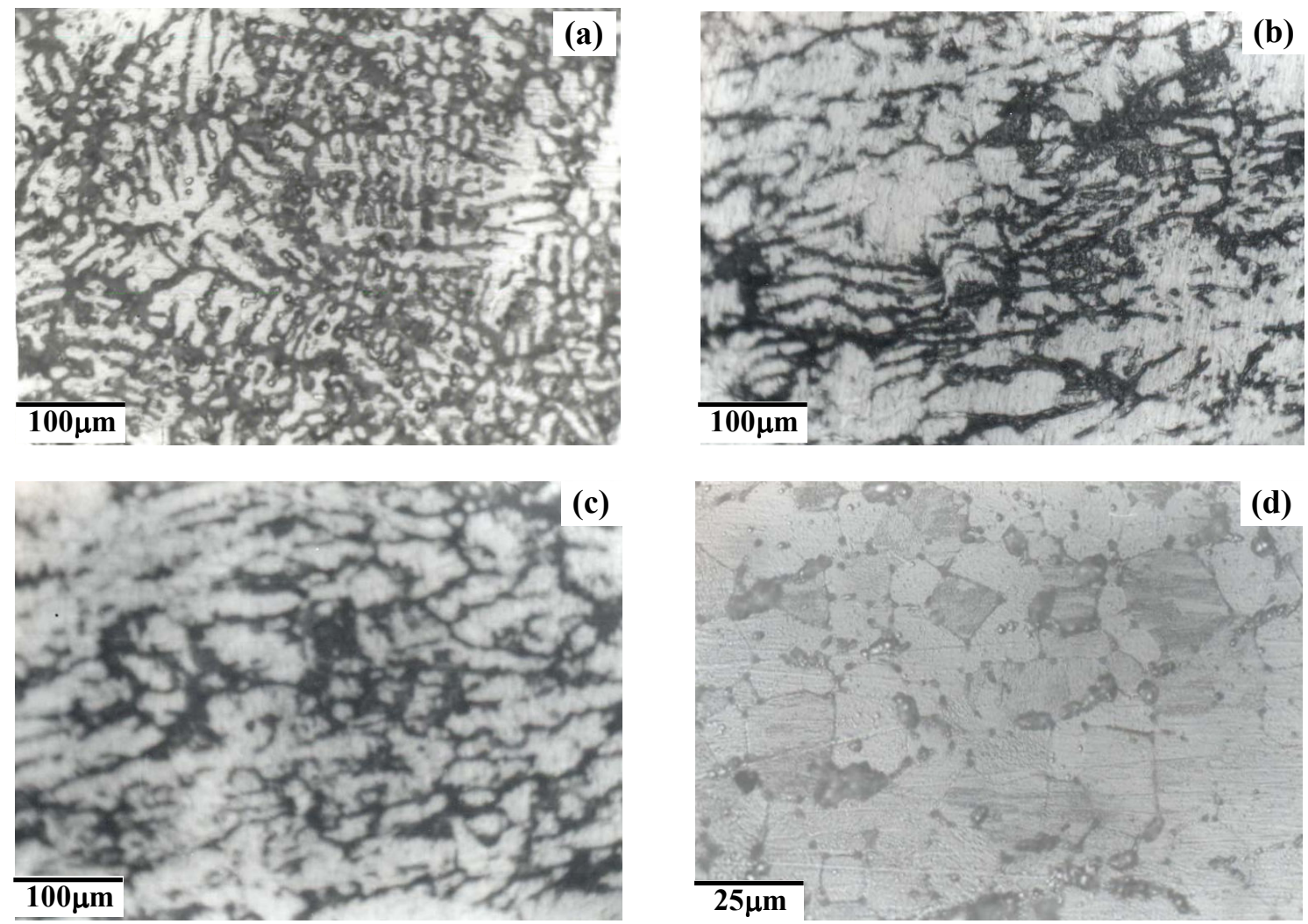

Figure 7. Optical micrograph of the a) cast alloy, b) $75 \%$ cold rolled alloy, c) $75 \%$ cold rolled alloy annealed at $300^{\circ} \mathrm{C}$ for one hour and d) $75 \%$ cold rolled alloy annealed at $400^{\circ} \mathrm{C}$ for one hour.

alloy shows relatively coarse non-uniform grain structure. The overall appearance is columnar grains with second phase particles remaining aligned along the grain boundaries (Fig. 7b). Fragmented dendrites, elongated along the direction of rolling are observed. When the cold rolled alloy is annealed at $300^{\circ} \mathrm{C}$ the amount of second phase decreases in quantity. However dendritic pattern is not removed fully from the microstructure. The second phase constituents are seen to be segregated mostly at the grain boundaries (Fig. 7c). If the cold rolled alloy is annealed at $400^{\circ} \mathrm{C}$, it is seen to be recrystallised almost fully (Fig. 7d). From the phase diagram of the alloy it is found that the present alloys would contain $\alpha+\beta$ eutectic within the primary dendrites of $\alpha$. Here ' $\alpha$ ' is the aluminium rich solid solution and $\beta$ is composed of intermetallics, primarily $\mathrm{Al}_{8} \mathrm{Mg}_{5}$ along with aluminides of other metals like iron, chromium, zirconium, manganese, which are present in small quantities in the aluminium used for the present experimentation. The number of non-equilibrium segregation is dependent on the magnesium content and the concentration of other potential aluminide formers ${ }^{8}$. Though general observations under optical microscopy have not provided much information, the overall appearance of the microstructure resembles what are normally observed in cast aluminium alloy ingot ${ }^{9}$. The cold worked alloy however has started recrystallising as it is known that recrystallisation of Al-6Mg alloy becomes completed at about $400^{\circ} \mathrm{C}^{7}$.

\section{SEM observation}

Scanning electron microstructures of the cast alloy substantiate the observations made in the study of optical microstructures. The cast alloy shows coarse dendrites with high quantity of second phase constituents. The second phase is found to be contained in the inter-dendritic space (Fig. 8a). The SEM microstructure of the hot rolled alloy studied in this investigation is shown in Fig. 8b. In the plate, non-uniform grain structure perpendicular to the rolling direction was developed. Fine, polygonal grains are observed in regions close to the plate edge, however the central part of the plate is characterized by elongated, recovered grains aligned in the bands separated by the highly deformed lamellar grains parallel to the rolling direction. Such non-uniform structure can be related to the non-homogeneous deformation characteristic for rolling as well as the processing conditions. The hot-rolling was carried on in the temperature range $380-385^{\circ} \mathrm{C}$, so the temperature of a final reduction was not sufficient to complete recrystallization. 

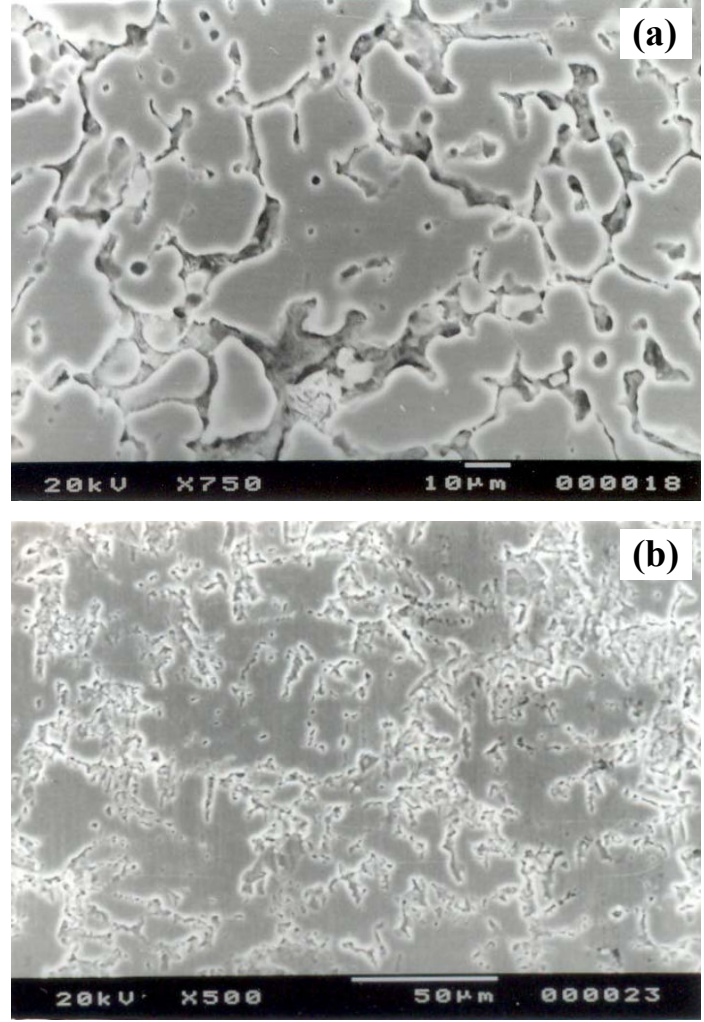

Figure 8. SEM micrograph of the a) cast alloy b) hot rolled alloy.

\section{TEM observation}

The microstructure of Al-6Mg alloy shows (Fig. 9) fine dispersoids with different morphologies. The Chinese script like intermetallics is reportedly $\alpha$-AlFeSi phase; the elongated needle shaped particles are $\beta-\mathrm{AlFeSi}$ and or $\mathrm{AlFe}$ phase having monoclinic crystal structure of low symmetry ${ }^{10}$. These crystals show specific habit and act as local stress raisers. Stress accommodation in surrounding matrix is accomplished through plastic deformation; this has led to the development of texture commensurate with the habit plane of the monoclinic phase.

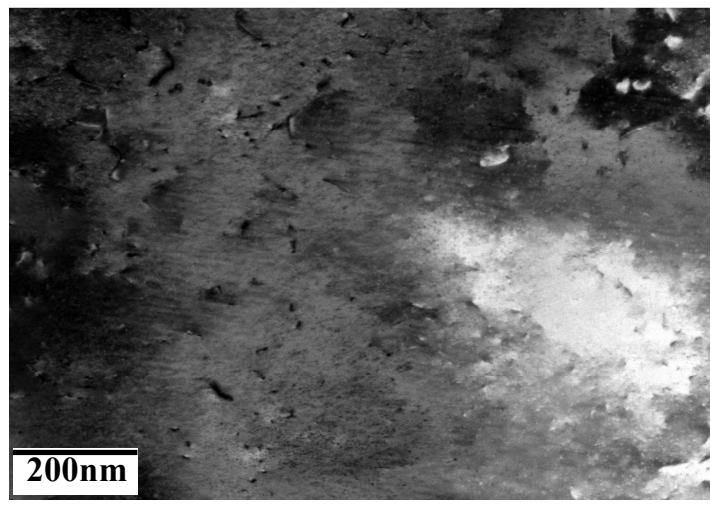

Figure 9. High resolution micrograph of the alloy showing dispersoids.

\section{CONCLUSIONS}

The hot rolling prior to cold rolling attends the higher strength due to precipitation of the $\beta^{\prime}$ and $\beta$ phase during hot rolling which hinder the dislocation movement. At higher temperature and time of annealing the electric resistivity of cold rolled alloys decreses due to particle coarcing but it increases for the cast alloy due to precipitation of $\beta$-phase. The cold worked structures are comprised of elongated grains to the rolling direction and it is seen to be recrystallised almost fully at $400^{\circ} \mathrm{C}$

\section{REFERENCES}

1. Polmear, I. J. "Light Alloys: Metallurgy of the Light Metals" Edward Arnold Publishers Ltd 41 Bedford Square, 1981, London WCIB 3DQ.

2. Mondolfo, L. F. "Aluminium Alloys: Structure and Properties" Print book English, 1976, Boston.

3. Myer, K., "Handbook of Materials Selection", John Wily and Sons,2002, New Yark. 32.

4. Adeosun, S. O., Ayoola, W. A., Bodude, M. and Sanni, S. O. "Strength and Hardness of DirectionallyRolled AA1230 Aluminum Alloy", Journal of Emerging Trends in Engineering and Applied Sciences, Vol. 2, No. 3, 2011, pp. 440-444.

5. Humphreys, F. J. and Hatherely, M. "Recrystallization and Related Annealing Phenomena" MaterialsScience and Engineering A, Vol. 205, 1996, pp. 187-198.

6. Radovic, L and Nikacevic, M. "Microstructure and Properties of Cold Rolled and Annealed Al-Mg Alloys", Scientific Technical Review, Vol. 58, No. 2, 2008, pp. 14-19.

7. Kaiser, M. S., "Effect of Scandium on the Softening behaviour of different degree of cold rolled Al-6Mg alloy annealed at Different Temperature" International Journal of Advances in Materials Science and Engineering, Vol. 1, No. 1, 2014, pp. 39-49.

8. Drits, M. E., Toropova, L. S., Anastas'eva, G. K. and Nagorniehnykh. G. I., "The effects of homogenizing heating on the properties of alloys in the Al-Sc and Al-Mg-Sc systems", Russ. Metall., No. 3, 1984, pp. 192-195.

9. Kaygorodova, L. I. and Domashnikov V.P., "Investigation of the influence of scandium on the Structure and Properties of an aluminium-magnesium alloy during natural ageing", Phys. Met. Metall. Vol. 68, No. 4, 1989, pp 160-166.

10. Sen, R., Ghosh, M. and Kaiser, M. S., "Microstructure-texture-fracture toughness property correlation in annealed $\mathrm{Al}-6 \mathrm{Mg}$ alloy with minor scandium and zirconium additions", Fatigue \& Fracture of Engineering Materials \& Structures, Vol. 35, No. 11, 2012, pp. 1071-1078. 